\title{
PET imaging with radiolabeled antibodies and tyrosine kinase inhibitors: immuno-PET and TKI-PET
}

\author{
Guus A. M. S. van Dongen • Alex J. Poot • \\ Danielle J. Vugts
}

Received: 19 October 2011 / Accepted: 3 January 2012 / Published online: 21 January 2012

(C) The Author(s) 2012. This article is published with open access at Springerlink.com

\begin{abstract}
During the last decade, the discovery of critical tumor targets has boosted the design of targeted therapeutic agents with monoclonal antibodies (mAbs) and tyrosine kinase inhibitors (TKIs) receiving most of the attention. Immuno-positron emission tomography (immuno-PET) and TKI-PET, the in vivo tracking and quantification of mAbs and TKIs biodistribution with PET, are exciting novel options for better understanding of the in vivo behavior and efficacy of these targeted drugs in individual patients and for more efficient drug development. Very recently, current good manufacturing practice compliant procedures for labeling of mAbs with positron emitters have been described, as well as the preparation of some radiolabeled TKIs, while the first proof of principle studies has been performed in patients. In this review, technical developments in immunoPET and TKI-PET are described, and their clinical potential is discussed. An overview is provided for the most appealing preclinical immuno-PET and TKI-PET studies, as well as the first clinical achievements with these emerging technologies.
\end{abstract}

Keywords Positron emission tomography · Monoclonal antibodies · Tyrosine kinase inhibitors · Zirconium-89 .

Fluorine-18 Carbon-11

G. A. M. S. van Dongen $(\bowtie) \cdot$ A. J. Poot $\cdot$ D. J. Vugts

Department of Otolaryngology/Head and Neck Surgery,

VU University Medical Center,

De Boelelaan 1117,

1081 HV Amsterdam, The Netherlands

e-mail: gams.vandongen@vumc.nl

G. A. M. S. van Dongen - A. J. Poot • D. J. Vugts

Department of Nuclear Medicine and PET Research,

VU University Medical Center,

De Boelelaan 1117,

1081 HV Amsterdam, The Netherlands

\section{Introduction}

Recent advances in molecular and cellular biology have resulted in the identification of critical molecular tumor targets involved in proliferation, differentiation, cell death and apoptosis, angiogenesis, immune recognition, invasion, and metastasis. In addition, critical molecular targets have been associated with cancer cell stemness. This knowledge has boosted the rational design of cutting-edge pharmaceuticals, with monoclonal antibodies (mAbs) and tyrosine kinase inhibitors (TKIs) forming the most rapidly expanding categories. Presently, $12 \mathrm{mAbs}$, all being intact immunoglobulins, and 12 TKIs have been approved by the US Food and Drug Administration for the systemic treatment of cancer (Table 1). The total yearly sales of mAbs and TKIs is estimated to be US $\$ 30$ and $\$ 16$ billion, respectively, mostly spent for the treatment of cancer, while hundreds of new $\mathrm{mAb}$ and TKI candidates are under clinical development by biotech and pharmaceutical companies [1].

The tremendous development of new targeted drugs might not only make optimism about future perspectives in the treatment of cancer but also raises the question about how to test all these drugs in an efficient way since in current drug development practice, it would require numerous clinical trials with large number of patients. Since just $10 \%$ of all anticancer drugs under clinical development will eventually reach the market, it becomes increasingly important to distinguish drugs with high potential from the ones with low potential at an early stage. This needs better understanding of the behavior and activity of those drugs in the human body. Furthermore, the effectiveness of current targeted therapies in oncology is limited, while their costs are excessive and therefore challenging the health care systems [2]. The questions are how to improve the efficacy of drug development by which drugs can become less 
Table $1 \mathrm{mAbs}$ and TKIs approved by FDA

\begin{tabular}{|c|c|c|}
\hline Generic name/year approved & Trade name & Target \\
\hline \multicolumn{3}{|c|}{ Monoclonal antibodies FDA-approved } \\
\hline Rituximab, 1997 & Rituxan & $\mathrm{CD} 20$ \\
\hline Trastuzumab, 1998 & Herceptin & HER2/neu \\
\hline Gemtuzumab ozogamicin, 2000 & Mylotarg & CD33 \\
\hline Alemtuzumab, 2001 & Campath-1H & CD52 \\
\hline${ }^{90}$ Y-Ibritumumab tiuxetan, 2002 & Zevalin & $\mathrm{CD} 20$ \\
\hline${ }^{131}$ I-Tositumomab, 2003 & Bexxar & $\mathrm{CD} 20$ \\
\hline Bevacizumab, 2004 & Avastin & VEGF \\
\hline Cetuximab, 2004 & Erbitux & EGFR \\
\hline Panitumumab, 2006 & Vectibix & EGFR \\
\hline Ofatumumab, 2009 & Arzerra & $\mathrm{CD} 20$ \\
\hline Ipilimumab, 2011 & Yervoy & CTLA-4 \\
\hline Brentuximab vedotin, 2011 & Adcetris & CD30 \\
\hline
\end{tabular}

Tyrosine kinase inhibitors FDA-approved

Gefitinib, 2003

Erlotinib, 2004

Sorafenib, 2005

Dasatinib, 2006

Sunitinib, 2006

Nilotinib, 2007

Lapatinib, 2007

Pazopanib, 2009

Vandetanib, 2011

Vemurafanib, 2011

Critozinib, 2011

$\begin{array}{ll}\text { Iressa } & \text { EGFR } \\ \text { Tarceva } & \text { EGFR }\end{array}$

Nexavar

VEGFR, PDGFR, RAF, Mek, Erk

Sprycel Src, ABL

Sutent

FLT3, PDGFR, VEGFR, KIT
Cancer indication

Lymphoma

Breast cancer

Acute myeloid leukemia

Chronic lymphatic leukemia

Non-Hodgkin's lymphoma

Non-Hodgkin's lymphoma

Colorectal cancer

Non-small cell lung cancer

Colorectal cancer

Head and neck cancer

Colorectal cancer

Chronic lymphocytic leukemia

Melanoma

Anaplastic large cell lymphoma Hodgkin lymphoma

Chronic myeloid leukemia Acute lymphoblastic leukemia Myelo dysplastic disease Myelo proliferative disease Hyper eosinophilic syndrome Chronic eosinophilic leukemia Gastrointestinal stromal tumor

Non-small cell lung cancer

Non-small cell lung cancer

Pancreatic cancer

Hepato cellular carcinoma

Renal cell carcinoma

Chronic myeloid leukemia

Acute lymphoblastic leukemia

Renal cell carcinoma

Gastrointestinal stromal tumor

Pancreatic cancer

Neuroendocrine tumors

Chronic myeloid leukemia

Breast cancer

Renal cell carcinoma

Thyroid cancer

Melanoma

Non-small cell lung cancer

$C D$ cluster of differentiation, $H E R 2 / n e u$ human epidermal growth factor receptor 2, VEGF vascular endothelial growth factor, $E G F R$ epidermal growth factor receptor, $P h C$ Philadelphia chromosome, $P D G F R$ platelet derived growth factor receptor, $C T L A-4$ cytotoxic T lymphocyte-associated antigen 4, ALK anaplastic lymphoma kinase, cMET MNNG HOS transforming gene, Erk extracellular regulated kinase, FLT3 Fms-like tyrosine kinase-3, $B R A F$ serine/threonine-protein kinase B-Raf, $B C R$ breakpoint cluster region gene, $A B L$ v-abl abelson murine leukemia viral oncogene homolog 
expensive, how to improve the efficacy of therapy with targeted drugs, and how to identify the patients with the highest chance of benefit from treatment with these drugs? In other words, when, how, and for whom should targeted therapy be reserved? To answer these questions, better insight in the in vivo behavior of therapeutic mAbs and TKIs should be obtained, including their interaction with critical disease targets, mechanism of action, and beneficial effects in individual patients. For this, positron emission tomography (PET) imaging with radiolabeled mAbs and TKIs is particularly attractive and better qualified than single photon emission computerized tomography (SPECT) imaging because it enables noninvasive whole body quantitative imaging of these targeted drugs at superior spatial and temporal resolution and sensitivity [3-6]. Whereas a typical PET scanner can detect between $10 \mathrm{e}-11 \mathrm{M}$ and $10 \mathrm{e}-12 \mathrm{M}$ concentrations, the sensitivity of a typical SPECT scanner is 10-50 times less as many photons are lost by the absorption of the SPECT collimators.

\section{Monoclonal antibodies and TKIs for treatment of cancer}

Currently, $12 \mathrm{mAbs}$ have been approved by the FDA for the treatment of cancer, all being intact mAbs [1]. Seven of the mAbs have been approved for the treatment of hematological malignancies, being rituximab, gemtuzumab ozogamicin, alemtuzumab, ibritumumab tiuxetan, tositumomab, ofatumumab, and brentuximab vedotin. Five mAbs have been approved for the therapy of solid tumors, and four of them interfere with signal transduction pathways by targeting growth factors or the extracellular domain of their receptors. Those mAbs comprise trastuzumab for the treatment of metastatic breast cancer; cetuximab, bevacizumab, and panitumumab for the treatment of colorectal cancer; and cetuximab and bevacizumab for the treatment of head and neck and non-small cell lung cancer. The fifth $\mathrm{mAb}$, ipilumumab, has an immunostimulatory effect via cytotoxic $\mathrm{T}$ lymphocyte-associated antigen 4 (CTLA-4) directed against melanoma. Most naked mAbs can also act via other effector mechanisms than described above such as antibodydependent cellular cytotoxicity, complement-dependent cellular cytotoxicity, or apoptosis induction. However, naked mAbs have limited efficacy on their own and should preferably be used in combination with chemo- or radiotherapy. Alternatively, mAbs can be loaded with toxic payloads like the radionuclides yttrium- 90 or iodine- 131 as in the case of ibritumumab tiuxetan and tositumomab, respectively, or with super toxic drugs as in the case of gemtuzumab ozogamycin and brentuximab vedotin. The use of supertoxic drugs is becoming increasingly popular, as illustrated by the approval of gemtuzumab ozogamycin and brentuximab vedotin (containing calicheamicin and auristatin as the supertoxic drug, respectively) and the development of the next generation anti-human epidermal growth factor receptor 2 (HER2) therapeutics such as trastuzumab-DM1 (trastuzumab coupled to the supertoxic drug mertansine) [7]. However, for highly toxic conjugates, selective tumor targeting is a must. Cross-reactivity of such supertoxic conjugates with normal tissues might result in unacceptable toxicity, as was recently demonstrated for the anti-CD44v6 conjugate bivatuzumab-DM1 [8].

In contrast to mAbs, TKIs are capable of entering the tumor cell where they compete for adenosine triphosphate (ATP) binding sites of transmembrane receptor tyrosine kinases, resulting in inhibition of signaling pathways. TKIs like gefitinib, erlotinib, and vemurafanib are monospecific and target just one tyrosine kinase, in this case epidermal growth factor receptor (EGFR), while all other FDAapproved TKIs are dual- or multispecific (see Table 1). Next to reversible TKIs, more recently, also irreversible TKIs are under investigation like the EGFR and HER2 inhibitors afatinib and neratinib $[9,10]$. In contrast to mAbs, TKIs are fast kinetic molecules without immune-mediated effector functions and are not suitable for the delivery of toxic payloads to tumors.

\section{The potential of immuno-PET and TKI-PET}

The ability of PET to quantitatively image the distribution of radiolabeled drugs within the body makes this technique a valuable tool at several stages of drug development and application. From first-in-man clinical trials with new drugs, it is important to learn about the ideal drug dosing for optimal tumor targeting (e.g., saturation of receptors), the uptake in critical normal organs to anticipate toxicity, and the interpatient variation in pharmacokinetics and tumor targeting. Drug imaging might provide this information in an efficient and safe way with fewer patients treated at suboptimal doses. Pretreatment imaging with the drug of interest might also have added value for patient selection because it can be used to assess target expression and drug accumulation in all tumor lesions and normal tissues noninvasively, quantitatively, and even over time. This information might be particularly relevant for heterogeneous tumor types or when targeted drugs are combined with other treatment modalities like chemo- and radiotherapy, to find routes of maximum synergism. Ideally, anatomical information on tumor extension is obtained, like possibly with PET$\mathrm{CT}$ and PET-MRI, to enable the assessment of homogeneity of tumor drug accumulation. Also, imaging during therapy is attractive to show that tumor targeting is effective and indeed results in antitumor effects as can be assessed by e.g., ${ }^{18} \mathrm{~F}$-fluorodeoxyglucose PET. If a targeted drug is not effective in a particular patient, adaptive treatment can be 
considered by dose escalation or by choosing targeted drugs that inhibit compensatory pathways. Apart from applications in treatment planning, treatment monitoring, and response monitoring, imaging with radiolabeled targeted drugs like mAbs can also be used for diagnostic purposes and for better understanding in vivo biology ("immunohistochemistry in vivo").

\section{Radiolabeling of mAbs for immuno-PET}

To enable visualization of a targeted drug with a PET camera, the drug should be labeled with a positron emitter in an inert way, i.e., that neither binding nor pharmacokinetic characteristics of the drug become altered. Moreover, the physical half-life of the positron emitter should be compatible with the residence time of the targeted drug in the body, which is typically several days for slow kinetic intact $\mathrm{mAbs}$ and a couple of hours for the fast kinetic small molecules like TKIs. Due to their large size of $150 \mathrm{kDa}$, it is quite easy to radiolabel $\mathrm{mAbs}$ for PET imaging in an inert way. Very recently, universal procedures were introduced for radiolabeling of intact $\mathrm{mAbs}$ with the long-lived positron emitters iodine-124 $\left({ }^{124} \mathrm{I}, t_{1 / 2}=100.3 \mathrm{~h}\right)$ [11] and zirconium$89\left({ }^{89} \mathrm{Zr}, t_{1 / 2}=78.4 \mathrm{~h}\right)[12]$, of which ${ }^{89} \mathrm{Zr}$ is particularly suitable in combination with internalizing mAbs. For radiolabeling of $\mathrm{mAb}$ fragments, which are more rapidly cleared from the body than intact $\mathrm{mAbs}$, short-lived positron emitters became available like gallium-68 $\left(t_{1 / 2}=1.13 \mathrm{~h}\right)$, copper-64 $\left(t_{1 / 2}=\right.$ $12.7 \mathrm{~h})$, yttrium-86 ( $\left.t_{1 / 2}=14.7 \mathrm{~h}\right)$, and bromine-76 $\left(t_{1 / 2}=16.2 \mathrm{~h}\right)$. Of these, the short-lived positron emitter gallium- $68\left({ }^{68} \mathrm{Ga}\right)$ is of particular clinical interest because it can be obtained from a commercially available long life-span ${ }^{68} \mathrm{Ge} /{ }^{68} \mathrm{Ga}$-generator (half-life 271 days), making it continuously available even for centers without a cyclotron and at reasonable costs. For some comprehensive reviews on positron emitters for immuno-PET, see references [13-15].

Due to the fact that most therapeutic mAbs are internalizing intact mAbs, ${ }^{89} \mathrm{Zr}$ nowadays becomes most broadly applied. To make this happen, crucial achievements have been obtained in the production $[12,16,17]$ and commercial availability of ${ }^{89} \mathrm{Zr}$ for clinical use [12], the development of a chelate for facile and stable coupling of ${ }^{89} \mathrm{Zr}$ to $\mathrm{mAbs}$ [18-20], and the development of protocols for labeling of mAbs with ${ }^{89} \mathrm{Zr}$ in a current good manufacturing practice (cGMP) compliant way [19]. In Europe, it takes 3-4 months of preparation before a ${ }^{89} \mathrm{Zr}$-labeled $\mathrm{mAb}$ can be evaluated in a clinical trial, including all the steps of setting up radiochemistry and quality controls in a cGMP compliant way, performing productions for validation of procedures, and taking regulatory hurdles.

During the past years, several preclinical and clinical ${ }^{124} \mathrm{I}$ - and ${ }^{89} \mathrm{Zr}$-immuno-PET studies have been performed with intact mAbs, for example, with mAbs U36 (antiCD44v6) [21], DN30 (anti-cMet) [22], G250 (anticarbonic anhydrase IX) [23-25], L19-SIP (antifibronectin) [11], R1507 (anti-IGF-1R) [26], J591 and 7E11 (antiprostatespecific membrane antigen (PSMA)) [27, 28], TCR105 (anti-CD105) [29], cetuximab (anti-EGFR) [30, 31], inbritumumab tiuxetan (anti-CD20) [32], rituximab (anti-CD20) [33], bevacizumab (anti-vascular endothelial growth factor (VEGF)) [34, 35], and trastuzumab (anti-HER2) [36-38].

\section{Radiolabeling of TKIs for TKI-PET}

In contrast to the radiolabeling of $\mathrm{mAbs}$, radiolabeling of small molecules $(<1 \mathrm{kDa})$ like TKIs is much more challenging and requires a drug-specific labeling strategy. In many cases, labeling with ${ }^{11} \mathrm{C}\left(t_{1 / 2}=20 \mathrm{~min}\right)$ will appear possible, while in some cases, the chemical structure of the drug will allow labeling with ${ }^{18} \mathrm{~F}\left(t_{1 / 2}=110 \mathrm{~min}\right)$. To increase chemical flexibility, radiolabeled TKI analogs are also used for PET imaging [5, 39]. However, to be sure that a PET tracer exactly represents the TKI of interest and to avoid extra regulatory hurdles, it is better to use labeling strategies that end up with exactly the original TKI chemical structure in which a cold carbon or fluorine atom has been substituted by ${ }^{11} \mathrm{C}$ or ${ }^{18} \mathrm{~F}$, respectively.

While mAbs are normally metabolically stable in the blood circulation and therefore radioactivity uptake in organs will represent mAb uptake, this can be different for radiolabeled TKIs. In case of TKIs, radioactive metabolites might be formed, which do not represent the biodistribution of the original TKI. The arising deviations can be depending on the position of the radioactive atom in the TKI. To this end, it might be interesting to label a TKI at different positions if possible and to select the most suitable candidate tracer. Nevertheless, before starting clinical trials with radiolabeled TKIs, the evaluation of their in vivo stability and the identification of metabolites are crucial, especially to make the quantification of TKI biodistribution possible.

Noninvasive in vivo quantification of TKIs in TKI-PET studies requires tracer kinetic models that describe uptake, retention, and clearance of the tracer in tissue. For this, the input function, i.e., the time course of the tracer in arterial plasma, should be known. Routinely, the time course of radioactivity in the whole blood and plasma is measured continuously using an online withdrawal and detection system. However, plasma usually contains labeled metabolites. The proper input function for the kinetic model is the metabolite-corrected plasma curve, and therefore at set times, additional discrete samples (usually seven during a 60-min scan) are collected to correct for labeled metabolites.

During the past years, procedures for radiolabeling of several FDA-approved anticancer TKIs have been described, 
including ${ }^{11} \mathrm{C}$-imatinib [40], ${ }^{11} \mathrm{C}$-gefitinib [41-43], ${ }^{18} \mathrm{~F}$-gefitinib [44, 45], ${ }^{18} \mathrm{~F}$-sunitinib [46], ${ }^{11} \mathrm{C}$-erlotinib [47], ${ }^{18} \mathrm{~F}$-lapatinib [48], and ${ }^{11} \mathrm{C}$-sorafenib [49]; however, only few of these tracers have been evaluated in animal models and just one in a clinical trial of which the results have not been published yet.

\section{Experiences with immuno-PET}

Preclinical immuno-PET has been used for different kinds of applications. Many studies have been focusing on the quantitative evaluation of mAbs for their capacity to target tumors selectively and on the assessment of the expression of critical tumor targets like CD20 [32, 33], CD105 [29], CD44v6 [21], cMet [22], PSMA [27, 28], IGF-1R [26], EGFR [30, 31], HER2 [36-38], and VEGF [34, 35]. In several of these studies, immuno-PET was evaluated for its suitability as scouting procedure prior to radioimmunotherapy to predict biodistribution and dosimetry of the corresponding therapeutic radioimmunoconjugates. For this purpose, the diagnostic radioimmunoconjugate should show a similar biodistribution as the therapeutic radioimmunoconjugate [50]. It was shown that ${ }^{89} \mathrm{Zr}$-ibritumumab tiuxetan is suitable for the prediction of ${ }^{90} \mathrm{Y}$-ibritumumab tiuxetan biodistribution [32], ${ }^{89} \mathrm{Zr}$-cetuximab for ${ }^{90} \mathrm{Y}$-cetuximab and ${ }^{177} \mathrm{Lu}$-cetuximab biodistribution [30], and ${ }^{124}$ I-L19-SIP for ${ }^{131}$ I-L19-SIP biodistribution [11]. In other studies, ${ }^{89} \mathrm{Zr}$-immuno-PET was evaluated for imaging and quantification of "therapeutic effect sensors" [6]. These are proteins whose expression is modulated in response to the functional inhibition of a drug target. For example, HER2 and VEGF are known to be downregulated upon Hsp90 inhibition, and their downregulation could indeed be visualized in vivo by the use of PET with ${ }^{89} \mathrm{Zr}$-trastuzumab [38] and ${ }^{89} \mathrm{Zr}$-bevacizumab [35], respectively. Therapeutic response upon chemo-, hormone-, and radiotherapy was also evaluated in another ${ }^{89} \mathrm{Zr}$-immuno-PET approach. Ruggiero et al. [28] used in their studies ${ }^{89} \mathrm{Zr}-7 \mathrm{E} 11$, a novel $\mathrm{mAb}$ directed against an intracellular epitope of PSMA. In vivo ${ }^{89} \mathrm{Zr}$-7E11 can only bind to PSMA in case dead or dying cells are present. The authors showed that ${ }^{89} \mathrm{Zr}$-7E11 can be used to monitor and quantify, with high specificity, tumor response upon therapy in PSMA-positive prostate tumors. In another approach, ${ }^{89} \mathrm{Zr}$-immuno-PET appeared suitable for imaging of tumor hypoxia. To this end, ${ }^{89} \mathrm{Zr}-\mathrm{cG} 250$ was used for detection of the membrane protein CAIX, which is involved in $\mathrm{pH}$ regulation and is upregulated in many tumors in case of hypoxia [25].

The disadvantage of using intact mAbs for confirmation of target expression with immuno-PET is their long residence time ranging from days to over weeks and the relatively low tumor-to-nontumor ratios at early time points after injection. In addition, the large size of a mAb molecule on one hand limits its diffusion from the vasculature into tumor, while on the other hand results in unspecific tumor uptake due to an enhanced permeability and retention effect. For this purpose, the use of $\mathrm{mAb}$ fragments or engineered proteins like diabodies and nanobodies might be an option. These fast kinetic antibody-based PET probes allow same-
Fig. 1 Immuno-PET images with ${ }^{89} \mathrm{Zr}$-cmAb U36 of head and neck cancer patient with a tumor on the right side of the soft palate and a lymph node metastasis at the left side of the neck (level III). Images were obtained $72 \mathrm{~h}$ post injection. a Coronal image of primary tumor. b Coronal image of lymph node metastasis in the neck. c Sagittal image of primary tumor. d Sagittal image of lymph node metastasis in the neck (from Börjesson et al. [21])
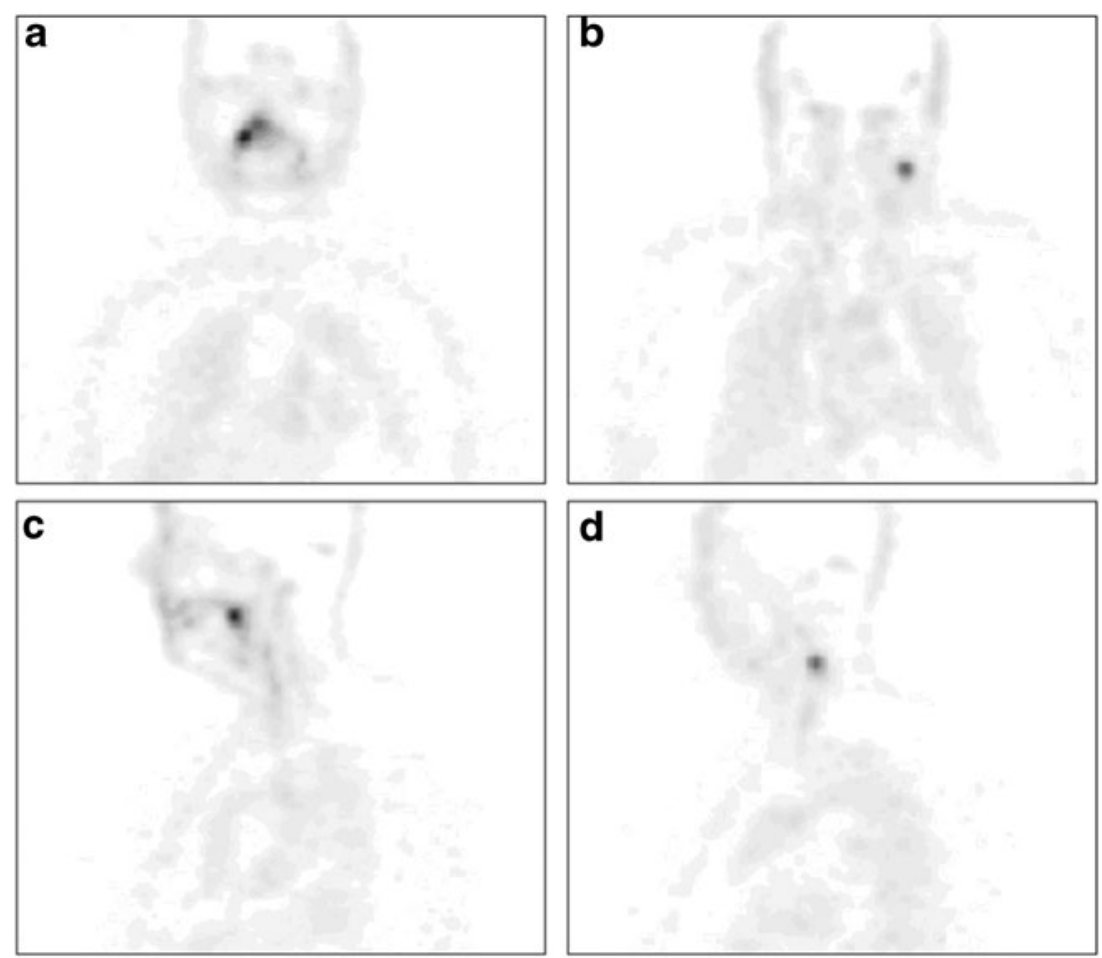
Fig. 2 Examples of

${ }^{89} \mathrm{Zr}$-trastuzumab uptake 5 days

p.i. in a patient with liver and

bone metastases (a) and two

patients with multiple bone

metastases $(\mathbf{b}, \mathbf{c})$. A number of

lesions have been specifically

indicated by the arrows

(from Dijkers et al. [36])
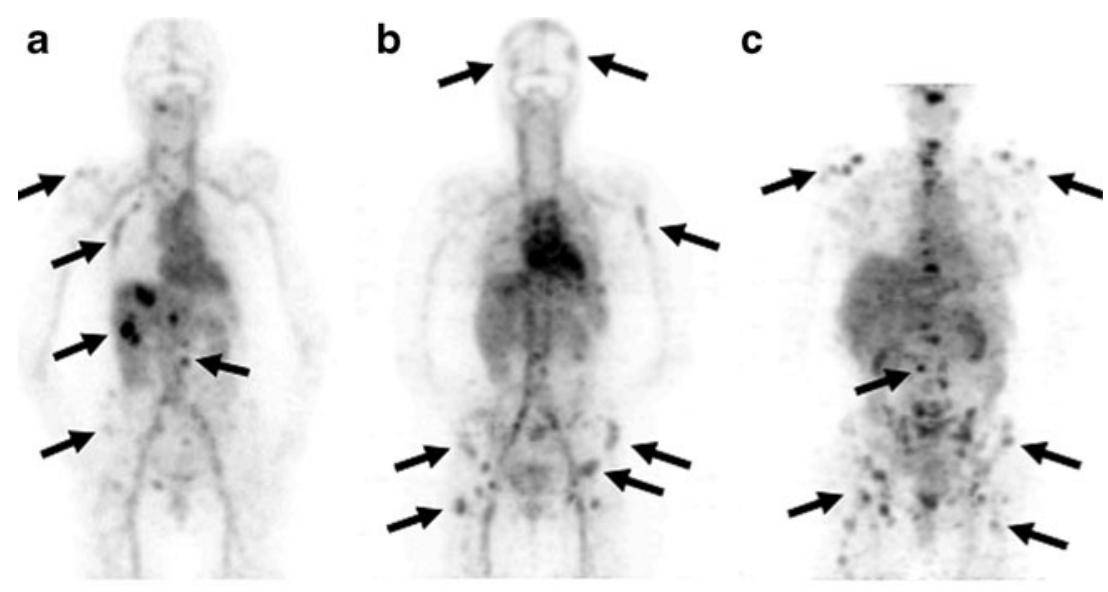

day imaging at low radiation burden for patients, to confirm target expression, as recently described by the group of $\mathrm{Wu}[51,52]$.

Some recent landmark studies also illustrate the potential of immuno-PET in clinical settings. ${ }^{124}$ I-immuno-PET was evaluated for in vivo profiling of renal cancer. Divgi et al. [24] used ${ }^{124} \mathrm{I}-\mathrm{cG} 250$ to predict the presence of clear-cell renal carcinomas in 25 patients scheduled for surgical tumor resection. It might be informative to identify those renal cancer patients who have this aggressive type because of treatment decisions. Of the 16 clear-cell patients, 15 were identified accurately by immuno-PET, and all 9 nonclearcell renal masses were negative for the tracer. This study illustrates how molecular imaging can contribute to personalized medicine.

The first clinical ${ }^{89} \mathrm{Zr}$-immuno-PET study ever was reported in 2006 by Börjesson et al. [21]. This feasibility study with 20 head and neck cancer patients showed that ${ }^{89} \mathrm{Zr}-\mathrm{cmAb}$, directed against CD44v6, can be safely applied in patients and that it is a promising tool for PET detection of primary tumors as well as of metastases in the neck (Fig. 1). In this study, biodistribution, radiation dose, and quantification potential of immuno-PET were also assessed [53]. PET quantification of blood-pool activity in the left ventricle was in good agreement with sampled blood activity, except for heavy weight patients $(>100 \mathrm{~kg})$. The same accounts for the uptake in tumor tissue, where a good agreement was observed between PET-derived data and biopsy data. This suggests that patients with high and low mAb uptake can be differentiated, which might be important for the selection of patients with the highest chance of benefit from mAb therapy.

High quality images were obtained by Dijkers et al. [37] in an immuno-PET study with ${ }^{89} \mathrm{Zr}$-trastuzumab in breast cancer patients. In this feasibility study with 14 patients, three different dose cohorts were evaluated: 10 or $50 \mathrm{mg}$ for trastuzumab-naïve patients and $10 \mathrm{mg}$ for patients on trastuzumab treatment. It was proven that the latter two performed equally. Although this study was not aiming for the comparison with conventional staging modalities or for assessing specificity and sensitivity, lesions with ${ }^{89} \mathrm{Zr}$-trastuzumab uptake were generally in good agreement with CT, MRI, and bone scans. PET images showed a high spatial resolution and a good signal-tonoise ratio, which resulted in an image quality unapproachable by previous ${ }^{111}$ In-trastuzumab SPECT scans. Excellent visualization of mAb uptake in HER2-positive lesions as well as in metastatic liver, lung, bone, and even brain HER2-positive lesions was observed (Fig. 2). ${ }^{89} \mathrm{Zr}$-trastuzumab PET allowed the quantification of conjugate uptake in HER2-positive lesions, and it became clear that for some patients with extensive tumor load, no HER2 saturation occurred during trastuzumab therapy. a

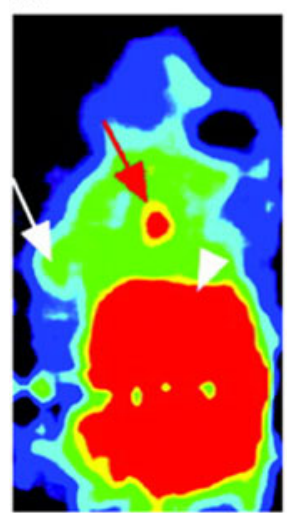

A549 b

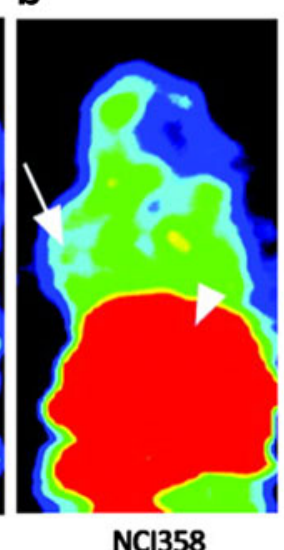

C

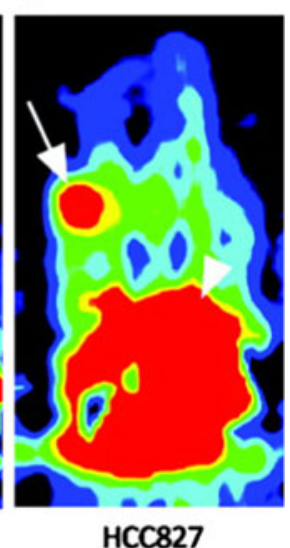

Fig. $3{ }^{11} \mathrm{C}$-erlotinib micro-PET imaging of lung cancer xenografts. Coronal micro-PET images of anesthetized athymic nude mice xenografted with A549 (a), NCI358 (b), and HCC827 (c) lung cancer cells at the left shoulder. A549 and NCI358 cell lines are less sensitive to erlotinib than HCC827, while the latter cell line harbors an inframe deletion mutation in exon 19 of EGFR. White arrows tumors. It can be concluded that the highest tumor uptake of ${ }^{11} \mathrm{C}$-erlotinib was found in the most sensitive xenograft line HCC827. The hot spot in a (red arrow) was found in all mice; however, it is not possible to show it in all mice as the tumors are located in different planes. Liver is seen with very high activity with spillover to the surrounding area (arrowheads) (derived from Memon et al. [47]) 


\section{Experiences with TKI-PET}

PET imaging might also contribute to better understanding of TKI activity, although preclinical in vivo proof of concept studies are scarce and thus far limited to ${ }^{11} \mathrm{C}$-gefitinib, ${ }^{18} \mathrm{~F}$ gefitinib, ${ }^{11} \mathrm{C}$-erlotinib, and ${ }^{11} \mathrm{C}$-sorafenib. The most appealing results have been obtained with erlotinib and gefitinib, which compete with ATP for the ATP-binding site on the EGFR, thereby preventing signal transduction leading to proliferation. Erlotinib and gefitinib can induce dramatic clinical responses but only in $4-10 \%$ of HNSCC patients and $10-15 \%$ of non-small-cell lung cancer (NSCLC) patients, when used as single agents [54]. Expression and mutation status of the EGFR have been associated with increased response [54]. It has been hypothesized that the presence of sensitizing mutations might increase the binding of the drug with its target. This might result in better drug retention within the tumor as well as in a more efficient inhibition of signaling through EGFR. However, for the assessment of EGFR expression and mutation status, a tumor biopsy has to be taken, which is not always possible like in NSCLC. Even when a biopsy is available, it is questionable whether this is sufficient to obtain a representative overview of the whole (often heterogeneous) tumor. Moreover, it is possible that expression and mutation status differ in primary tumor and metastatic lesions and change during the course of disease, for example, upon chemo- or radiotherapy. Taking this into account, it might be that PET imaging with the radiolabeled EGFR TKI itself gives a more comprehensive overview of EGFR receptor status and the interaction of the drug with this receptor. To test this possibility, Memon et al. [47] evaluated the uptake of ${ }^{11} \mathrm{C}$-erlotinib in nude mice bearing lung cancer xenograft lines with a different sensitivity to erlotinib treatment and a different mutation status. In mice carrying the most sensitive xenograft line, a xenograft line with a mutation in EGFR, tumor uptake of ${ }^{11} \mathrm{C}$-erlotinib was the highest, indicating that ${ }^{11} \mathrm{C}$-erlotinib PET can indeed identify erlotinib sensitive tumors (Fig. 3).

\section{Conclusion}

mAbs and TKIs are forming the most rapidly expanding categories of targeted therapies; however, the efficacy of these drugs is still quite limited, with benefit for just a portion of patients. Immuno-PET and TKI-PET are attractive for studying the in vivo behavior of therapeutic mAbs and TKIs and their interaction with critical disease targets because it enables quantitative imaging of these drugs at high resolution and sensitivity. Review of the literature shows that immuno-PET and TKI-PET might form an attractive tool to allow better understanding of targeted therapy efficacy, more efficient drug development, and more patient-tailored therapy.

Open Access This article is distributed under the terms of the Creative Commons Attribution Noncommercial License which permits any noncommercial use, distribution, and reproduction in any medium, provided the original author(s) and source are credited.

\section{References}

1. Walsh G. Biopharmaceutical benchmarks. Nat Biotechnol. 2010;28:917-24.

2. Mano M. The burden of scientific progress: growing inequalities in the delivery of cancer care. Acta Oncol. 2006;45:84-6.

3. Van Dongen GAMS, Visser GWM, Lub-de Hooge MN, De Vries EG, Perk LR. Immuno-PET: a navigator in monoclonal antibody development and applications. Oncologist. 2007;12:1379-89.

4. Van Dongen GAMS, Vosjan MJWD. Immuno-positron emission tomography: shedding light on clinical antibody therapy. Cancer Biother Radiopharm. 2010;25:375-85.

5. Tolmachev V, Stone-Elander S, Orlova A. Radiolabelled receptortyrosine-kinase targeting drugs for patient stratification and monitoring of therapy response: prospects and pitfalls. Lancet Oncol. 2010;11:992-1000.

6. De Vries EGE, Oude Munnink TH, Van Vugt MATM, Nagengast WB. Towards molecular imaging-driven drug development in oncology. Cancer Discovery. 2011. doi:10.1158/2159-8274.CD-11-0051.

7. Lewis Phillips GD, Li G, Dugger DL, Crocker LM, Parsons KL, Mai E, et al. Targeting HER2-positive breast cancer with trastuzumab-DM1, an antibody-cytotoxic drug conjugate. Cancer Res. 2008;68:9280-90.

8. Tijink BM, Buter J, De Bree R, Giaccone G, Lang MS, Staab A, et al. A phase I dose escalation study with anti-CD44v6 bivatuzumab mertansine in patients with incurable squamous cell carcinoma of the head and neck or esophagus. Clin Cancer Res. 2006;12:606472.

9. Yap TA, Vidal L, Adam J, Stephens P, Spicer J, Shaw H, et al. Phase I trial of the irreversible EGFR and HER2 kinase inhibitor BIBW 2992 in patients with advanced solid tumors. J Clin Oncol. 2010;28:3965-72.

10. Sequist LV, Besse B, Lynch TJ, Miller VA, Wong KK, Gitlitz B, et al. Neratinib, an irreversible pan-ErbB receptor tyrosine kinase inhibitor: results of a phase II trial in patients with advanced non-small-cell lung cancer. J Clin Oncol. 2010;28:3076-83.

11. Tijink BM, Perk LR, Budde M, Stigter-van Walsum M, Visser GWM, Kloet RW, et al. ${ }^{124}$ I-L19-SIP for immuno-PET imaging of tumour vasculature and guidance of ${ }^{131} \mathrm{I}$-L19-SIP radioimmunotherapy. Eur J Nucl Med Mol Imaging. 2009;36:1235-44.

12. Verel I, Visser GWM, Boellaard R, Stigter-van Walsum M, Snow $\mathrm{GB}$, Van Dongen GAMS. ${ }^{89} \mathrm{Zr}$ immuno-PET: comprehensive procedures for the production of ${ }^{89} \mathrm{Zr}$-labeled monoclonal antibodies. J Nucl Med. 2003;44:1271-81.

13. Nayak TK, Brechbiel MW. Radioimmunoimaging with longerlived positron-emitting radionuclides: potentials and challenges. Bioconjug Chem. 2009;20:825-41.

14. Tolmachev V, Stone-Elander S. Radiolabelled proteins for positron emission tomography: pros and cons of labelling methods. Biochim Biophys Acta. 2010;1800:487-510. 
15. Holland JP, Williamson MJ, Lewis JS. Unconventional nuclides for radiopharmaceuticals. Mol Imaging. 2010;9:1-20.

16. Holland JP, Sheh Y, Lewis JS. Standardized methods for the production of high specific-activity zirconium-89. Nucl Med Biol. 2009;36:729-39.

17. Walter M, Gebhardt P, Grosse-Gehling P, Würbach L, Irmler I, Preusche $\mathrm{S}$, et al. Implementation of ${ }^{89} \mathrm{Zr}$ production and in vivo imaging of B-cells in mice with ${ }^{89} \mathrm{Zr}$-labeled anti-B-cell antibodies by small animal PET/CT. Appl Radiat Isot. 2011;69:852-7.

18. Perk LR, Vosjan MJWD, Visser GWM, Budde M, Jurek P, Kiefer GE, et al. p-Isothiocyanatobenzyl-desferrioxamine: a new bifunctional chelate for facile radiolabeling of monoclonal antibodies with zirconium-89 for immuno-PET imaging. Eur J Nucl Med Mol Imaging. 2009;37:250-9.

19. Vosjan MJWD, Perk LR, Visser GWM, Budde M, Jurek P, Kiefer GE, et al. Conjugation and radiolabeling of monoclonal antibodies with zirconium-89 for PET imaging using the bifunctional chelate p-isothiocyanatobenzyl-desferrioxamine. Nat Protoc. 2010;5:739-43.

20. Tinianow JN, Gill HS, Ogasawara A, Flores JE, Vanderbilt AN, Luis E, et al. Site-specifically ${ }^{89} \mathrm{Zr}$-labeled monoclonal antibodies for ImmunoPET. Nucl Med Biol. 2010;37:289-97.

21. Börjesson PKE, Jauw YWS, Boellaard R, De Bree R, Comans EFI, Roos JC, et al. Performance of immuno-positron emission tomography with zirconium-89-labeled chimeric monoclonal antibody U36 in the detection of lymph node metastases in head and neck cancer patients. Clin Cancer Res. 2006;12:2133-40.

22. Perk LR, Stigter-van Walsum M, Visser GWM, Kloet RW, Vosjan MJWD, Leemans CR, et al. Quantitative PET imaging of Met-expressing human cancer xenografts with ${ }^{89} \mathrm{Zr}$-labelled monoclonal antibody DN30. Eur J Nucl Med Mol Imaging. 2008;35:1857-67.

23. Brouwers A, Verel I, Van Eerd J, Visser GWM, Steffens MG, Oosterwijk E, et al. PET radioimmunoscintigraphy of renal cell cancer using ${ }^{89} \mathrm{Zr}$-labeled cG250 monoclonal antibody in nude rats. Cancer Biother Radiopharm. 2004;19:155-63.

24. Divgi CR, Pandit-Taskar N, Jungbluth AA, Reuter VE, Gönen M, Ruan S, et al. Preoperative characterisation of clear-cell renal carcinoma using iodine-124-labelled antibody chimeric G250 (124I-cG250) and PET in patients with renal masses: a phase I trial. Lancet Oncol. 2007;8:304-10.

25. Hoeben BAW, Kaanders JHAM, Franssen GM, Franssen GM, Troost EGC, Rijken PFJW, et al. PET imaging of hypoxia with ${ }^{89} \mathrm{Zr}$-labeled cG250-F(ab')2 in head and neck tumors. J Nucl Med. 2010;51:1076-83.

26. Heskamp S, Van Laarhoven HW, Molkenboer-Kuenen JD, Franssen GM, Versleijen-Jonkers YM, Oyen WJ, et al. ImmunoSPECT and immunoPET of IGF-1R expression with the radiolabeled antibody $\mathrm{R} 1507$ in a triple-negative breast cancer model. J Nucl Med. 2010;51:1565-72.

27. Holland JP, Divilov V, Bander NH, Smith-Jones PM, Larson SM, Lewis JS. ${ }^{89} \mathrm{Zr}$-DFO-J591 for ImmunoPET of prostate-specific membrane antigen expression in vivo. J Nucl Med. 2010;51:1293-300.

28. Ruggiero A, Holland JP, Hudolin T, Shenker L, Koulova A, Bander $\mathrm{NH}$, et al. Targeting the internal epitope of prostatespecific membrane antigen with ${ }^{89} \mathrm{Zr}$-7E11 Immuno-PET. J Nucl Med. 2011;52:1-8.

29. Hong H, Severin GW, Yang Y, Engle JW, Zhang Y, Bernhardt TE, et al. Positron emission tomography imaging of CD105 expression with ${ }^{89} \mathrm{Zr}$-Df-TRC105. Eur J Nucl Med Mol Imaging. 2011. doi:10.1007/s00259-011-1930-x.

30. Perk LR, Visser GWM, Vosjan MJWD, Stigter-van Walsum M, Tijink BM, Leemans CR, et al. ${ }^{89} \mathrm{Zr}$ as a PET surrogate radioisotope for scouting biodistribution of the therapeutic radiometals ${ }^{90} \mathrm{Y}$ and ${ }^{177} \mathrm{Lu}$ in tumor-bearing nude mice after coupling to the internalizing antibody cetuximab. J Nucl Med. 2005;46:1898-906.

31. Aerts HJWL, Dubois L, Perk L, Vermaelen P, Van Dongen GAMS, Wouters BG, et al. Disparity between in vivo EGFR expression and ${ }^{89} \mathrm{Zr}$-labeled cetuximab uptake assessed with PET. J Nucl Med. 2009;50:123-31.

32. Perk LR, Visser OJ, Stigter-van Walsum M, Vosjan MJWD, Visser GWM, Zijlstra JM, et al. Preparation and evaluation of ${ }^{89} \mathrm{Zr}$ Zevalin for monitoring of ${ }^{90} \mathrm{Y}-Z$ evalin biodistribution with positron emission tomography. Eur J Nucl Med Mol Imaging. 2006;33:1337-45.

33. Muylle K, Azerad MA, Perk LR, Meuleman N, Delrieu V, Ghanem $\mathrm{G}$, et al. Immuno-PET/CT imaging with $\mathrm{Zr}$-89-rituximab as a prelude for radioimmunotherpy with Y-90-rituximab in patients with relapsed CD20+ B cell non-Hodkin's lymphoma. Ann Oncol. 2008;19:179-80.

34. Nagengast WB, De Vries EG, Hospers GA, Mulder NH, De Jong $\mathrm{JR}$, Hollema $\mathrm{H}$, et al. In vivo VEGF imaging with radiolabeled bevacizumab in a human ovarian tumor xenograft. J Nucl Med. 2007;48:1313-9.

35. Nagengast WB, De Korte MA, Oude Munnink TH, TimmerBosscha H, Den Dunnen WF, Hollema H, et al. Lub-de Hooge M, Schröder CP, De Vries EGE. ${ }^{89} \mathrm{Zr}$-bevacizumab PET of early antiangiogenic tumor response to treatment with HSP90 inhibitor NVP-AUY922. J Nucl Med. 2010;51:761-7.

36. Dijkers ECF, Kosterink JGW, Rademaker AP, Perk LR, Van Dongen GAMS, Bart J, et al. Development and characterization of clinical grade ${ }^{89} \mathrm{Zr}$-trastuzumab for HER2/neu immunoPET imaging. J Nucl Med. 2009;50:974-81.

37. Dijkers EC, Oude Munnink TH, Kosterink JG, Brouwers AH, Jager PL, De Jong JR, et al. Biodistribution of ${ }^{89} \mathrm{Zr}$-trastuzumab and PET imaging of HER2-positive lesions in patients with metastatic breast cancer. Clin Pharmacol Ther. 2010;87:586-92.

38. Holland JP, Caldas-Lopes E, Divilov V, Longo Va, Taldone T, Zatorska $\mathrm{D}$, et al. Measuring the pharmacodynamic effects of a novel Hsp90 inhibitor on HER2/neu expression in mice using ${ }^{89}$ Zr-DFO-trastuzumab. PLoS One. 2010;5:e8859.

39. Glekas AP, Pillarsetty NK, Punzalan B, Khan N, Smith-Jones P, Larson SM. In vivo imaging of Bcr-Abl overexpressing tumors with a radiolabeled imatinib analog as an imaging surrogate for imatinib. J Nucl Med. 2011;52:1301-7.

40. Kil K-E, Ding Y-S, Lin K-S, Alexoff D, Kim SW, Shea C, et al. Synthesis and positron emission tomography studies of carbon-11labeled imatinib (Gleevec). Nucl Med Biol. 2007;34:153-63.

41. Wang J-Q, Gao M, Miller KD, Sledge GW, Zheng Q-H. Synthesis of $\left[{ }^{11} \mathrm{C}\right]$ Iressa as a new potential PET cancer imaging agent for epidermal growth factor receptor kinase. Bioorg Med Chem Lett. 2006;16:4102-6.

42. Holt DP, Ravert HT, Dannals RF, Pomper MG. Synthesis of $\left[{ }^{11} \mathrm{C}\right]$ gefitinib for imaging epidermal growth factor receptor tyrosine kinase with positron emission tomography. J Lab Compd Radiopharm. 2006;49:883-8.

43. Zhang M-R, Kumata K, Hatori A, Takai N, Toyohara J, Yamasaki $\mathrm{T}$, et al. $\left[{ }^{11} \mathrm{C}\right]$ Gefitinib $\left[{ }^{11} \mathrm{C}\right]$ Iressa: radiosynthesis, in vitro uptake, and in vivo imaging of intact fibrosarcoma. Mol Imaging Biol. 2010;12:181-91.

44. Seimbille Y, Phelps ME, Czernin J, Silvermann DHS. Fluorine-18 labeling of 6,7-disubstituted anilinoquinazoline derivatives for positron emission tomography (PET) imaging of tyrosine kinase receptors: synthesis of $\left[{ }^{18} \mathrm{~F}\right]$-Iressa and related molecular probes. $\mathrm{J}$ Label Compd Radiopharm. 2005;48:829-43.

45. Su H, Seimbille Y, Feri GZ, Bodenstein C, Fueger B, Kim KJ, et al. Evaluation of $\left[{ }^{18} \mathrm{~F}\right]$-gefitinib as a molecular imaging probe for the assessment of the epidermal growth factor receptor status in malignant tumors. Eur J Nucl Med Mol Imaging. 2008;35:1089-99. 
46. Wang J-Q, Miller KD, Sledge GW, Zheng Q-H. Synthesis of $\left[{ }^{18} \mathrm{~F}\right]$ SU11248, a new potential PET tracer for imaging cancer tyrosine kinase. Bioorg Med Chem Lett. 2005;15:4380-3.

47. Memon AA, Jakobsen S, Dagnaes-Hanen F, Sorensen BS, Keiding S, Nexo E. Positron emission tomography (PET) imaging with $\left[{ }^{11} \mathrm{C}\right]$-labeled erlotinib: a micro-PET study on mice with lung tumor xenografts. Cancer Res. 2009;69:873-8.

48. Basuli F, Wu H, Li C, Shi Z-D, Sulima A, Griffith GL. A first synthesis of ${ }^{18} \mathrm{~F}$-lapatinib: a potential tracer for positron emission tomography imaging of Erb1/Erb2 tyrosine kinase activity. J Label Compd Radiopharm. 2011;54:633-6.

49. Asakawa C, Ogawa M, Kumata K, Fujinaga M, Kato K, Yamasaki $\mathrm{T}$, et al. $\left[{ }^{11} \mathrm{C}\right]$ Sorafenib: radiosynthesis and preliminary PET study of brain uptake in P-gp/Bcrp knockout mice. Bioorg Med Chem Lett. 2011;21:2220-3.
50. Verel I, Visser GWM, Van Dongen GAMS. The promise of immuno-PET in radioimmunotherapy. J Nucl Med. 2005;46 Suppl $1: 164 \mathrm{~S}-71$.

51. Olafsen T, Wu AM. Antibody vectors for imaging. Semin Nucl Med. 2010;40:167-81.

52. McKabe $\mathrm{K}, \mathrm{Wu}$ AM. Positive progress in immunoPET — not just a coincidence. Cancer Biother Radiopharm. 2010;25:253-61.

53. Börjesson PKE, Jauw YWS, de Bree R, Roos JC, Castelijns JA, Leemans CR, et al. Radiation dosimetry of ${ }^{89} \mathrm{Zr}$-labeled chimeric monoclonal antibody U36 as used for immuno-PET in head and neck cancer patients. J Nucl Med. 2009;50:182836.

54. Shepherd FA, Rodrigues Pereira J, Ciuleanu T, Tan EH, Hirsh V, Thongprasert S, et al. Erlotinib in previously treated non-small-cell lung cancer. N Engl J Med. 2005;353:123-32. 